\title{
Preparation and characterization of microporous poly(D,L-lactic acid) film for tissue engineering scaffold
}

This article was published in the following Dove Press journal:

International Journal of Nanomedicine

23 November 2010

Number of times this article has been viewed

\section{Shuai Shi \\ Xiu Hong Wang \\ Gang Guo \\ Min Fan \\ Mei Juan Huang \\ Zhi Yong Qian}

State Key Lab of Biotherapy and Cancer Center, West China Hospital, West China Medical School, Sichuan University, Chengdu, PR China
Correspondence: Zhi Yong Qian State Key Lab of Biotherapy and Cancer Center, West China Hospital, West China Medical School, Sichuan University, Chengdu, 6I004I, PR China Tel +862885164063

Fax +862885164060

Email anderson-qian@163.com

\begin{abstract}
We prepared a series of microporous films based on poly(D,L-lactic acid) (PLA) via phase separation. According to scanning electron microscopy (SEM), a 3-dimensional foamy structure with multimicrometer scale pores on the air surface of film could be observed. As the morphology of PLA film could not be stabilized using solvent-nonsolvent phase separation, we investigated the effect of temperature, air movement, and concentration on the properties of microporous PLA films. The results show that when the temperature was $25^{\circ} \mathrm{C}$ in a vacuum, it was easy to prepare PLA film with micropores, and it was stable. As the relationship between the morphology and formation factors was clear and the morphology of the PLA film was controllable, we studied the PLA film's potential use for cell culture. SEM results showed that NIH3T3 cell could be adhered on the surface of film well after incubation for 2 days. Meanwhile, in vitro culture experiments revealed the great biocompatibility of the scaffold for adsorption and proliferation of fibroblasts.
\end{abstract}

Keywords: poly(D,L-lactic acid), scaffold, phase separation, cell culture

\section{Introduction}

Tissue engineering is defined as the application of principles and methods of engineering and life sciences for the development of biological substitutes to restore, maintain, or improve tissue function. ${ }^{1}$ To achieve the major goal of tissue engineering, three basic elements are required: an appropriate cell source, a biodegradable scaffold, and optimal culture conditions. ${ }^{2}$ As a fundamental element, scaffolds are designed to induce autogeneic tissues regeneration or to develop biological substitutes for defective tissues through cell culture in vitro, and, in fact, the potential use of a tissue engineering scaffold depends primarily on the structure and characters of the material. To find the potential use of a macromolecules polymer on tissue engineering, many methods have been used, such as electrospinning, replica molding technique, and gelation..$^{3-6}$ The feasibility of these methods is largely dependent on the scaffold properties such as biocompatibility, degradability, highly interconnected porosity, and mechanical integrity. ${ }^{7,8}$ As one of the most successfully used methods, phase separation has been widely used in the preparation of scaffold for many years. ${ }^{9-12} \mathrm{~A}$ variety of routes for the preparation of porous, biodegradable film or scaffolds have been developed in the past few years. ${ }^{13-16}$ The method of solvent-nonsolvent (SNS) phase separation is one of the most convenient routes to prepare multiporous scaffolds with micro/nanoscale pores on the air surface, and these structures have enhanced the hydrophilicity of the films and scaffolds; however, it is difficult to control microforms using poly(D,L-lactic acid) (PLA). ${ }^{17,18}$ 
Many biodegradable types of polyesters, such as polyglycolic acid and poly( $\varepsilon$-caprolactone), have been used in clinical applications for a very long time. ${ }^{19}$ The bulk degradation property of PLA means that it can be used for cellular scaffold in vitro and in vivo in tissue engineering. ${ }^{20}$ In the past years, much work had been carried out to prepare and evaluate PLA membranes or fibers for application as the scaffold for human cell growth in tissue engineering. ${ }^{12,21,22}$

In this study, to control the prepared results and obtain a novel scaffold structure for cell culture and tissue engineering, we investigated the factors that could affect the microforming of PLA film and prepared a PLA scaffold with microporous structure. We found that the speed of solvent volatilization has a crucial effect on the formation of scaffold, and we also detected the cell attachment and proliferation on this microporous scaffold.

\section{Materials and methods Materials}

PLA (MW = 160,000; detected by gel permeation chromatography), glycerol, ethylene glycol (EG), tetrahydrofuran (THF), and methylene chloride (DCM) were purchased from Chendu KeLong Chemicals (Chengdu, China). 3-(4,5-dimethylthiazol-2-yl)-2,5-diphenyltetrazolium bromide (MTT; Sigma, St Louis, MO) and acridine orange (AO; Sigma) were used.

\section{Preparation of microporous PLA film}

PLA films at various PLA concentrations $(5 \%, 10 \%$, and $15 \%, \mathrm{w} / \mathrm{v}$ ) were prepared by phase separation. Briefly, $1 \mathrm{mg}$ of PLA was first dissolved in $5 \mathrm{~mL}$ of DCM at room temperature. After PLA was completely dissolved, $10 \mathrm{~mL}$ of THF was then added into the mixed solution at $55^{\circ} \mathrm{C}$ to ablate DCM by volatilization. Since PLA was uniformly dissolved in THF, the solution was added dropwise onto the surface of EG/glycerin (Glc) mixed solution. Finally, the system was placed in the fume hood for volatilization overnight, and the microporous PLA film was obtained. After washing the film with distilled water several times and drying by baking, the final product was preserved in a tower dryer before further application.

\section{Morphologic observation}

The morphology of these prepared PLA porous films was observed through SEM, which was performed using FEI Inspect F (Philips, Eindhoven, the Netherlands) equipment operated at $20 \mathrm{kV}$.

\section{Contact angle measurements}

The apparent water-in-air contact angles of the PLA microporous films were measured by the sessile drop method using a Krüss DSA 100 goniometer (Krüss, Hamburg, Germany) at room temperature; $3 \mu \mathrm{L}$ of deionized water was dropped on the sample surfaces. At least 5 measurements were performed at different locations and the results averaged.

\section{Open porosity of microporous film}

According to the description of Kuo et al, porosity of the PLA scaffold was evaluated using trimmed samples of $2.8 \mathrm{~cm}^{2} \times 0.6 \mathrm{~cm}$ into ethanol. ${ }^{23}$ The porosity $(P(\%))$ is calculated using the following formula:

$$
P(\%)=\frac{V_{\mathrm{c}}}{V_{\mathrm{m}}} \times 100 \%=\left(W_{24}-W_{0}\right) \times \frac{\rho}{V_{\mathrm{m}}} \times 100 \%,
$$

where $V_{\mathrm{m}}$ is the total volume of PLA scaffold $\left(\mathrm{cm}^{3}\right), V_{\mathrm{c}}$ is the pore volume of the PLA scaffold $\left(\mathrm{cm}^{3}\right), W_{24}$ is the weight of PLA scaffold (g) after incubation with ethanol for $24 \mathrm{~h}$, $W_{0}$ is the original weight of PLA scaffold ( $\mathrm{g}$ ), and $\rho$ is the density of the ethanol $\left(0.789 \mathrm{~g} \times \mathrm{cm}^{-3}\right)$.

The above test was performed in triplicate for each kind of scaffold fabricated in this study.

\section{Cell culture and attachment}

In this part, we chose the PLA scaffold prepared at the concentration of $10 \%$ and used the multiporous film as the scaffold. The NIH3T3 cell was obtained from ATCC (Manassas, VA) and cultured with Dulbecco's modified Eagle's medium at $37^{\circ} \mathrm{C}$ and $5 \% \mathrm{CO}_{2}$. As PLA scaffolds were placed in 24-well plates, the NIH3T3 cells were seeded on the scaffolds at a density of 400 cells/well, and after incubation for 12 or $72 \mathrm{~h}$, the mediums were replaced by fresh complete medium every 2 days. The cells sticking were observed through SEM. The PLA film containing cells was removed from the wells and washed twice in phosphate-buffered saline (PBS) and then fixed with $2.5 \%$ glutaraldehyde at $\mathrm{pH} 7.4$ overnight. After rinsing in $0.1 \mathrm{~mol}$ PBS, specimens were then dehydrated in increasing concentrations of ethanol. Dehydrated specimens were immersed in hexamethyldisilazane (Chendu KeLong Chemicals) for $15 \mathrm{~min}$ in a desiccator. After drying, the specimens were mounted on aluminum stubs, sputter-coated with goldpalladium, and viewed in a Philips XL-20 SEM (Philips) with an accelerating voltage of $20 \mathrm{kV}$. 


\section{Analysis of cell cytotoxicity and proliferation}

The cell cytotoxicity and proliferation were determined by MTT assay and AO stain. In this method, we also chose the PLA scaffold prepared at the concentration of $10 \%$ and used the multiporous film as the scaffold.

In MTT assay, MTT was used to assess cell cytotoxicity and proliferation by measuring mitochondrial succinate dehydrogenase activity. First, cells were seeded in 24-well plates at a density of $1 \times 10^{5}$ cells/well in $1 \mathrm{~mL}$ growth medium in a humidified atmosphere with $5 \% \mathrm{CO}_{2}$, and the cells in wells without a scaffold served as the negative control. After 1, 2 and 4 days, MTT solution $(200 \mu \mathrm{L})$ ( $5 \mathrm{mg} / \mathrm{mL}$; Sigma) was added to corresponding wells and cultured at $37^{\circ} \mathrm{C}$ for $4 \mathrm{~h}$ to allow the formation of formazan crystals. The MTT solution was then removed, films were washed with PBS, and dimethylsulfoxide $(750 \mu \mathrm{L})$ was added into each well. The well plate was left on a shaking platform for $10 \mathrm{~min}$. Thereafter, the solution $(150 \mu \mathrm{L})$ was collected and pipetted into a 96-well plate. The absorbance was recorded on a microplate reader (Bio-Rad, Hercules, CA), using a test wavelength of $570 \mathrm{~nm}$. The cell viability (\%) was related to the control wells and was demonstrated according to the OD value. All data are presented as the mean of the measurements $( \pm \mathrm{SD})$.

In fluorescent staining and observation, at each time point, the samples were stained using $0.01 \%$ AO (Sigma) for $5 \mathrm{~min}$, washed twice using PBS, and observed under a fluorescence microscope (DMI6000 B, GER; Leica, Wetzlar, Germany). For each time point, the test was performed in triplicate.

\section{Statistical analysis}

The data were analyzed statistically using a Tukey's multiple range post-hoc test with SPSS for Windows (version 16.0; SPSS Inc., Chicago, IL). Statistical tests were performed at a 95\% significance level $(P<0.05)$.

\section{Results}

\section{Morphological analysis and roughness}

Using the SNS phase separation method, we prepared a series of PLA films (Figure 1). It is easy to prepare multiporous film using SNS phase separation; however, the micromorphology of the prepared films was not identical. We believe that temperature as well as air movement were the main factors affecting the preparation of films. These factors affected the speed of the phase separation and made the prepared films different. In order to understand this relationship clearly, we prepared films at various conditions and investigated the differences; meanwhile, the surface and cross-section of obtained film was observed with SEM, which is shown in the figures.

\section{Preparation method}

According to the previous report, ${ }^{17}$ the method of SNS phase separation is indeed a simple route to prepare multiporous film. In this study, we compared the morphology of the films prepared via SNS phase separation, with the films prepared naturally via volatilization. The morphology observation shown in Figure 2 indicates that the pore appearance in different films are conspicuously different and that the films prepared via SNS phase separation had a smoother surface, both in thin and thick films.

\section{Temperature}

The volatility of THF at different temperatures was not concordant, and for this reason, we obtained various PLA films with disparate morphology shown in Figure 3. We observed the scaffold prepared at $4^{\circ} \mathrm{C}, 25^{\circ} \mathrm{C}$, and $50^{\circ} \mathrm{C}$, and at $25^{\circ} \mathrm{C}$, the film had unique micropores on its air surface. This experiment showed an ambient temperature is beneficial for shaping the surface of the scaffold with multipores, and the obtained films were more smooth at a low speed of phase separation. That is to say, a moderate rate of evaporation is beneficial for formation of droplets of the solvent, and after these droplets volatilized, spherical holes appeared and occupied the interface.

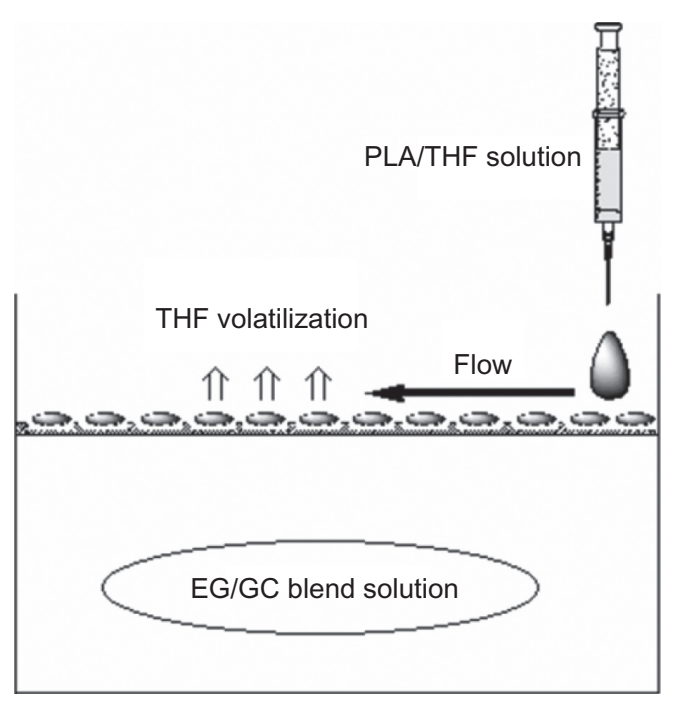

Figure I A schematic illustration of preparation of PLA scaffold with microporous structure.

Abbreviations: EG, ethylene glycol; GC, THF, tetrahydrofuran; PLA, poly (D,L-lactic acid). 


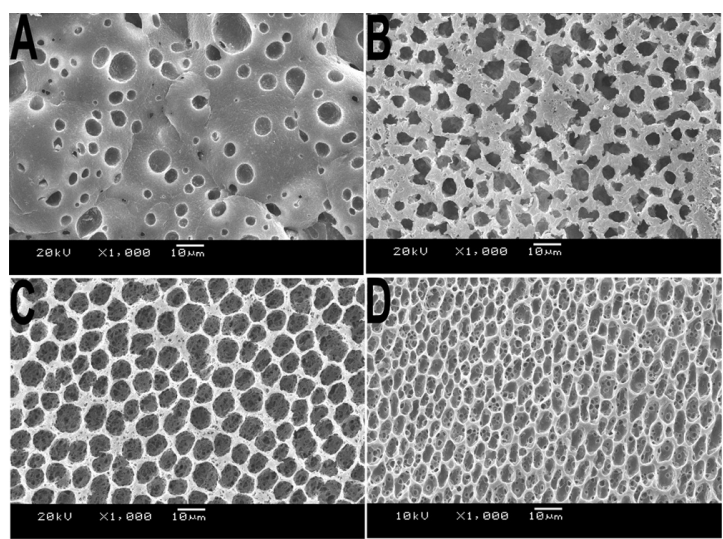

Figure 2 SEM of morphology of PLA film prepared via different methods. A) Volatilization naturally; film prepared via SNS phase separation at the concentration of B) $5 \%$, C) $10 \%$, and D) $15 \%$. All samples were prepared at room temperature without air.

Abbreviations: PLA, poly(D,L-lactic acid); SEM, scanning electron microscope; SNS, solvent-nonsolvent.

\section{Air movement}

As many factors could affect the morphology of the scaffold macroscopically and microscopically, we made many changes during the preparation process. The results obtained showed that air movement was a fundamental condition. Air movement could affect the volatilization of the THF and thus affect the speed of the phase separation. As shown in Figure 4, at $25^{\circ} \mathrm{C}$ we prepared three types of scaffold by controlling the air movement. In order to obtain a smooth membrane without shrinkage, the air movement around the separation interface should not be strong.

After many factors had been studied, we used SNS phase separation by controlling the temperature at $25^{\circ} \mathrm{C}$ and decreasing the speed of air movement to obtain a PLA

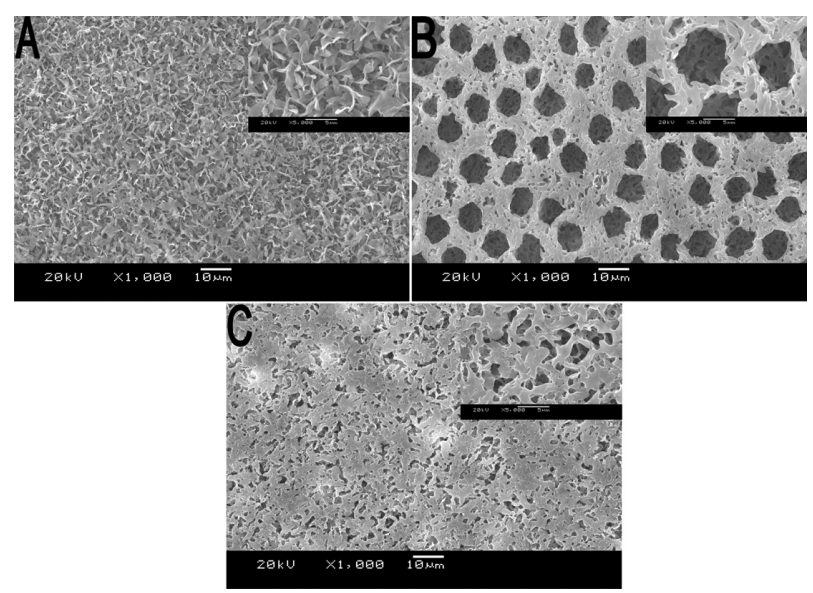

Figure 3 SEM micrographs of various types of PLA porous scaffold prepared at different temperatures. A) $4^{\circ} \mathrm{C}$, B) $25^{\circ} \mathrm{C}$, and C) $50^{\circ} \mathrm{C}$. Inset: images of corresponding scaffold at higher magnification

Abbreviations: PLA, poly(D,L-lactic acid); SEM, scanning electron microscope. film with multiporous air surface and porous structure (Figure 5).

\section{Water contact angle}

Water contact angle was used to characterize the hydrophilicity and water uptake of PLA. The water contact angles of PLA at different concentrations were 126.24 (5\%), 111.38 (10\%), and 104.86 (15\%) (Table 1), and it was observed that the water uptake of PLA scaffolds increased with the increase in PLA concentration.

\section{Open porosity}

The open porosity of PLA microporous scaffold at different concentrations is shown in Table 1. The open porosity of PLA microporous scaffold at $5 \%$ concentration $(\mathrm{w} / \mathrm{v})$ was $60 \%$, at $10 \%$ concentration $(\mathrm{w} / \mathrm{v})$ was $46 \%$, and at $15 \%$ concentration (w/v) was $38 \%$, which was much lower than that of PLA at $5 \%$.

\section{NIH3T3 attachment, spreading, and proliferation}

All the films used in cell culture studies were prepared at $25^{\circ} \mathrm{C}$ without air movement outside the beaker, and the concentrations were all 10\% (w/v). The SEM photographs of NIH3T3 cells attached on the porous PLA scaffold cultured for 72 and $12 \mathrm{~h}$ are shown in Figure 6. The samples were dehydrated using the increasing concentration of alcohol and the critical point drying method. The results indicate that the porous PLA scaffold shows a good cell attachment.

Figure 7 shows the cell proliferation on PLA scaffolds and indicates the scaffold with low cytotoxicity. The OD

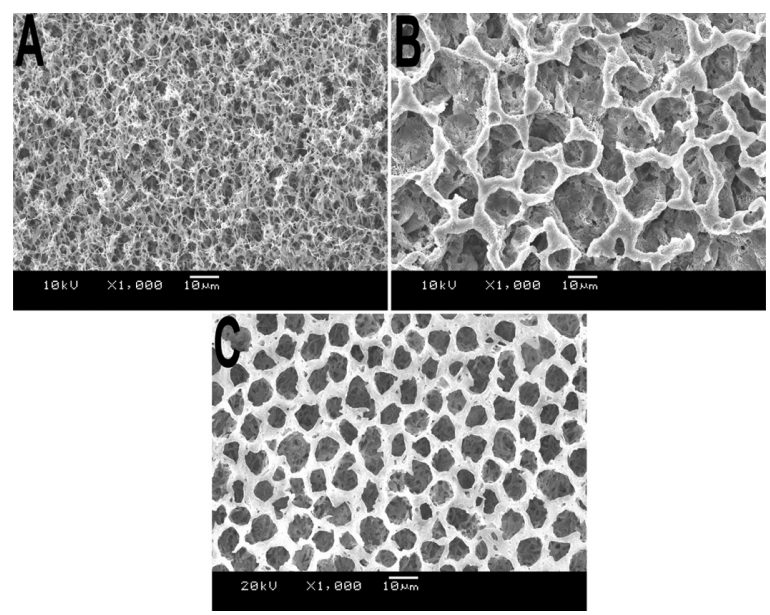

Figure 4 SEM images of PLA scaffolds prepared with various types of ventilation. A) Hermetic environment, B) open environment without air, and C) open environment with ventilated pumping equipment.

Abbreviations: PLA, poly(D,L-lactic acid); SEM, scanning electron microscope. 


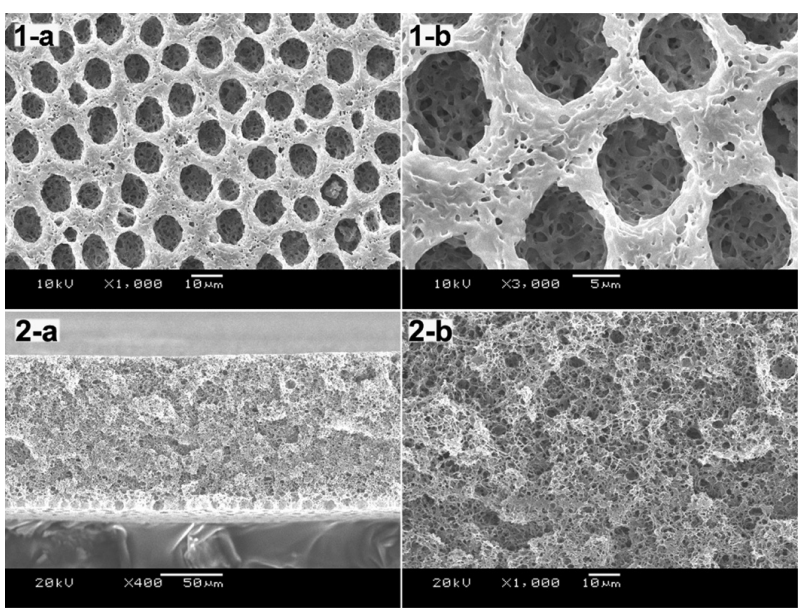

Figure 5 SEM images of PLA scaffolds prepared at $25^{\circ} \mathrm{C}$ with the concentration of $10 \%(w / v)$. Morphology observation of PLA film included the air face and cross-section: I-a) air face of 10\% PLA film, I000x; I-b) air surface of 10\% PLA film, 3000x; 2-a) cross-section of 10\% PLA film, 400x; 2-b) cross-section of 10\% PLA film, 1000x. Abbreviations: PLA, poly(D,L-lactic acid); SEM, scanning electron microscope.

value indicated the number of cells in each well. Cultured from the first day to the fourth day, cells proliferated well on various scaffolds.

A scaffold with 3D structure is critical as it promotes cell-cell proximity and enhances self-assembly tissue function. To study the growth and development traits of NIH3T3 cells on PLA scaffolds, cells were first stained by $\mathrm{AO}$ and observed through a fluorescence microscope. Figure 8 shows the cell growth and proliferation. After culturing for 1, 2, and 4 days, NIH3T3 were stained with AO for $5 \mathrm{~min}$, and then photographs were taken. As the time increased, the cells proliferated from 1 to 2 days and then 4 days.

\section{Discussion}

Since PLA is a semicrystalline polymer, it can be crystallized during the SNS phase separation, which has been reported previously. ${ }^{18}$ As many factors could affect the speed of phase separation, several films with different microshapes were made on their air surface. In this study, a series of microporous PLA films were prepared using phase separation under different conditions, and all of them were observed by SEM.

Table I Water contact angles and open porosity of the PLA scaffolds in different concentrations

\begin{tabular}{lll}
\hline Sample & Contact angle & Open porosity \\
\hline $5 \%$ PLA (w/v) & $126.24 \pm 3.37$ & $68.79 \pm 8.64$ \\
$10 \%$ PLA (w/v) & $111.38 \pm 4.02$ & $46.13 \pm 5.19$ \\
I5\% PLA (w/v) & $104.86 \pm 10.17$ & $38.52 \pm 1.16$ \\
\hline
\end{tabular}

Notes: All of the data are the average of 5 measurements.

Abbreviation: PLA, poly(D,L-lactic acid).

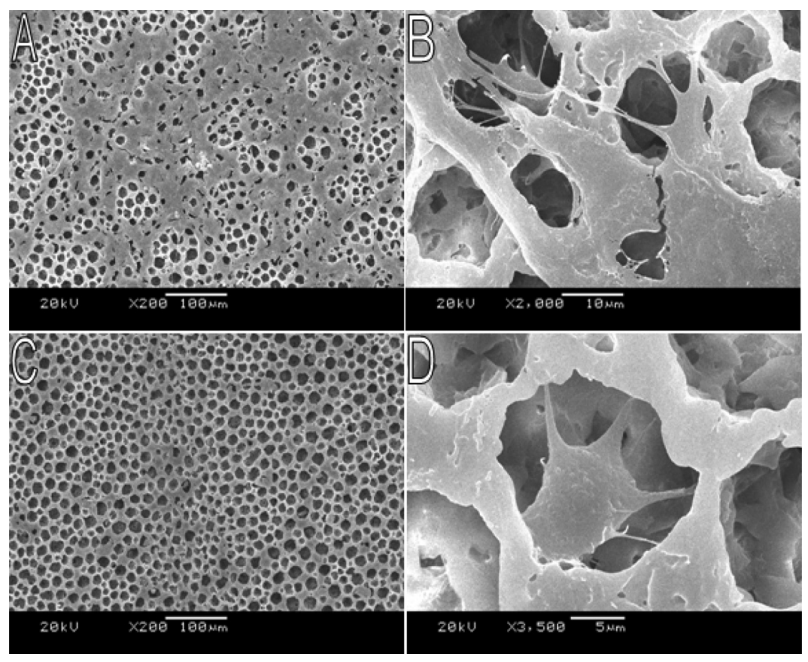

Figure 6 SEM photographs showing morphology of NIH3T3 cells cultured on PLA scaffold. A) Cells cultured for 3 days, 200x; B) Cells cultured for 3 days, 2000x; C) Cells cultured for 12 h, 200x; D) Cells cultured for 12 h, 3500x.

Abbreviations: PLA, poly(D,L-lactic acid); SEM, scanning electron microscope.

As the morphology of the prepared film was under control, the potential application for tissue engineering was also studied. Two-dimensional or 3-dimensional (3D) ordered nano/microstructure porous scaffolds possess high specific surface area and ordered arrangement and thus have extensive applications in cell tissue engineering, such as bone tissue engineering and epidermal regeneration. In addition, the thickness and face structure of these films or scaffolds can be controlled by controlling the volume of the solution dropwise and vapor deposition. Thus, such 3D porous films would be good candidates for new cell culture scaffolds, and the scaffolds can be modulated based on the main controllable parameters for forming requirement structure, such as temperature, solution

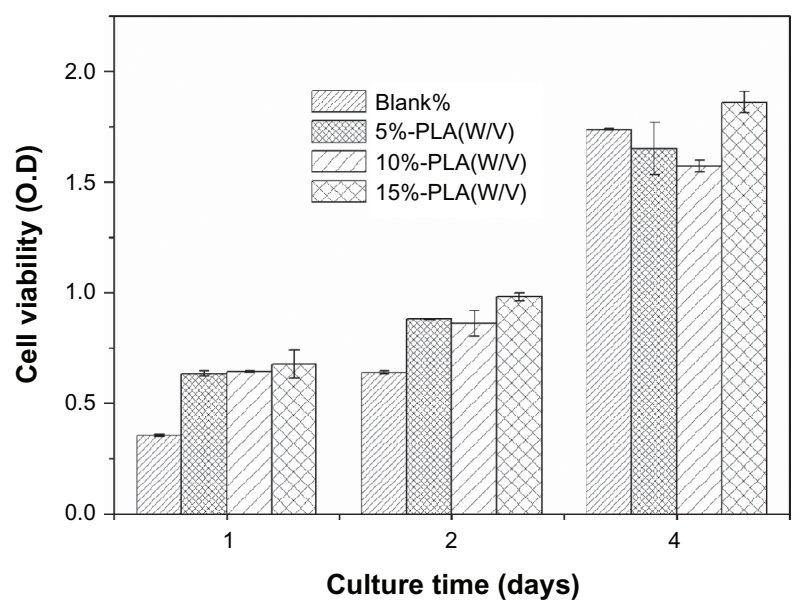

Figure $7 \mathrm{NIH} 3 \mathrm{~T} 3 \mathrm{~s}$ proliferation on porous PLA scaffolds. The number of cells was normalized to initial density of seeded cells $\left(I \times 10^{5}\right.$ cells/well). Mean for $\mathrm{n}=3 \pm$ SD.

Abbreviations: PLA, poly(D,L-lactic acid); SD, standard deviation. 


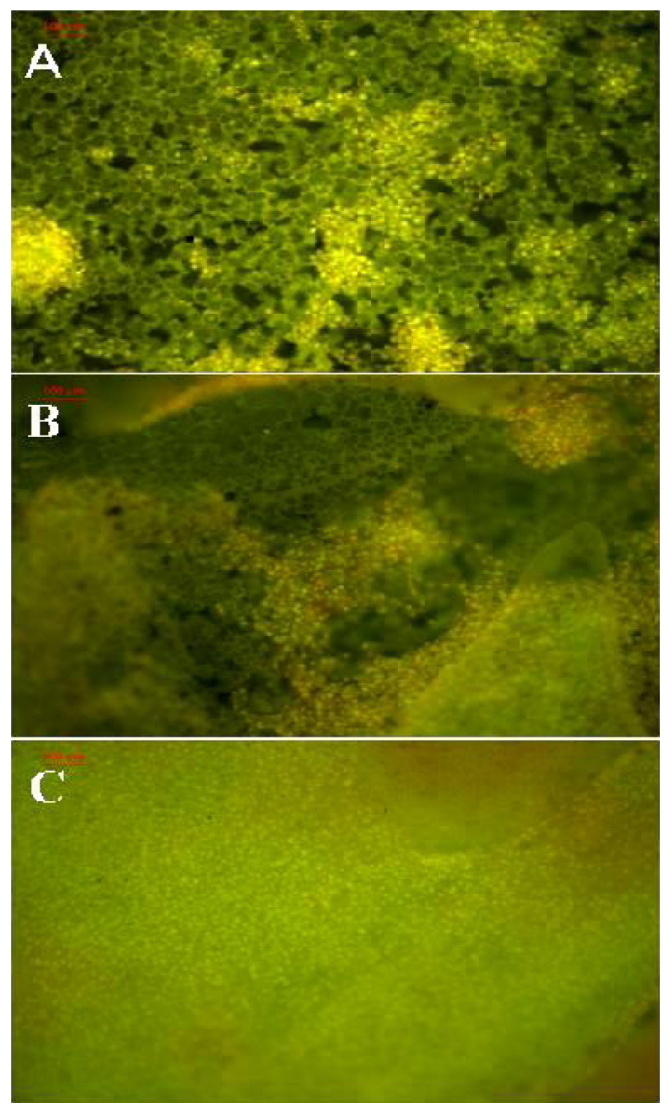

Figure 8 Fluorescence microscopy images of $\mathrm{NIH} 3 \mathrm{~T} 3$ cells cultured on A) I, B) 2, and C) 4 days. The cells were stained by acridine orange stain.

concentration, and volume of the drops; these factors are usually correlated with each other. The preparation of scaffold based on such multiporous films with regular structure and smooth appearance, as well as separately controllable effect factors over a large range, is a great challenge. Solving this problem will be a big step toward forming scaffolds with stable structures and their practical application in cell culture.

In this study, we identify the main factors for forming porous structure, including temperature and air movement, and in short, it is the speed of the solution volatilization. In PLA solutions volatilized in fuming cupboard, the films had corrugated profiles, while in immovable or airtight environments, the films obtained were flat. In addition, flat films showed various face microstructures with the change in the speed of solution volatilization. An exceedingly slow volatilization of the solution makes the surface more crystallized, which makes it unsuitable for forming liquid droplet on the air face to obtain a honeycombed structure.

With the increase in PLA concentration, the viscosity of PLA in THF solution increased and mobility gradually weakened. Thus, in the membrane preparation process, relatively thick films were obtained at the high concentration, and the water contact angles may be affected as shown in Table 1. During measurement of the contact angle, we found that water droplets slowly progressed deeper into the membrane and the tension increased. The open porous rate of the membrane at low concentration has a higher open porous rate, which might also induce a decline in the membrane strength (Table 1).

Previously, Karim et al mentioned thin polymer films with flattened droplets, and this could be affirmed by an interfacial free energy minimization argument. ${ }^{21}$ PLA porous scaffolds prepared in this study had a honeycomb surface, and due to the free energy minimization in the interface, we obtained a microporous structure as shown by SEM. With regard to the application of the biodegradable film for cell culture substrates, it is recognized that the surface structures and the scaffold's amphiphilic character has a significant influence on the adhesion, migration, and proliferation of cells. Cell adhesion and migration depend on the sedimentation of the serum protein, as the cells are connected through the serum protein. In this study, we investigated the pure PLA scaffold with porous structures and regular surface. The structures shown in Figures 2-5 suggest that the rapid solidification of the PLA after phase separation is necessary to gain open pores at the membrane surface. In addition, although different factors caused various surface structures, including regularly fibrosing prominence and honeycombed porous intercession, the scaffolds were both confirmed to be biocompatible, which had been demonstrated by MTT assay and AO stain.

Although the thin films had regular structures and the thickness was easily controlled, some limitations of these films should also be pointed out. For example, tensile strength is the main limitation for application in vivo. As PLA is recrystallized during this preparation and the films obtained had porous structure, the PLA scaffolds lack rigidity and can be easily fractured with little effort. In addition, the size of the pore in the surfface of the film is difficult to control, and this is related to the material used and the preparation method.

In summary, using the SNS method of phase separation to obtain porous structure scaffold is a simple route, and by controlling the speed of volatilization, we could obtain an uniform surface structure scaffold. The PLA scaffold is compatible with cell culture with low cytotoxicity. The observations presented in this study suggest a PLA structure and its use in cell culture. In further studies, a PLA scaffold blend or chemical modification with other polymers should be studied in vitro and in vivo to develop clinically useful scaffolds for cell tissue engineering. 


\section{Conclusion}

In this study, we prepared a porous PLA scaffold through phase separation, and by controlling the environmental factors, we obtained a scaffold that had a multipore face and spongiform cross-structure. The cell culture studies indicated a significant increase in cell spreading and proliferation; the spongiform scaffolds reveal good cell absorbency and could be used as a novel structure for seeding cells. However, as we used simple PLA as the forming material, the scaffolds obtained do not have potential application in clinical tissue engineering because of the limitation of the tenacity.

\section{Acknowledgments}

This work was financially supported by National 863 project (2007AA021902), New Century Excellent Talents in University (NCET-08-0371), and Chinese Key Basic Research Program (2010CB529906). In addition, we thank Wang Hui (Analytical and Testing Center, Sichuan University) for her great help in SEM observation.

\section{Disclosure}

The authors report no conflicts of interest in this work.

\section{References}

1. Langer R, Vacanti JP. Tissue engineering. Science. 1993; 260(5110):920-926.

2. Yoshimoto H, Shin YM, Terai H, Vacanti JP. A biodegradable nanofiber scaffold by electrospinning and its potential for bone tissue engineering. Biomaterials. 2003;24(12):2077-2082.

3. Drury JL, Mooney DJ. Hydrogels for tissue engineering: scaffold design variables and applications. Biomaterials. 2003;24(24):4337-4351.

4. You Y, Min BM, Lee SJ, Lee TS, Park WH. In vitro degradation behavior of electrospun polyglycolide, polylactide, and poly (lactide-co-glycolide). J Appl Polym Sci. 2005;95(2):193-200.

5. Choi NW, Cabodi M, Held B, Gleghorn JP, Bonassar LJ, Stroock AD. Microfluidic scaffolds for tissue engineering. Nat Mater. 2007;6(11):908-915.

6. Neeley WL, Redenti S, Klassen H, et al. A microfabricated scaffold for retinal progenitor cell grafting. Biomaterials. 2008;29(4):418-426.
7. Tabata Y. The importance of drug delivery systems in tissue engineering. Pharm Sci Technolo Today. 2000;3(3):80-89.

8. Malafaya PB, Silva GA, Baran ET, Reis RL. Drug delivery therapies I: general trends and its importance on bone tissue engineering applications. Curr Opin Solid State Mater Sci. 2002;6(4):283-295.

9. van de Witte P, Dijkstra PJ, van den Berg JWA, Feijen J. Phase separation processes in polymer solutions in relation to membrane formation. J Memb Sci. 1996;117(1-2):1-31.

10. Nam YS, Park TG. Biodegradable polymeric microcellular foams by modified thermally induced phase separation method. Biomaterials. 1999;20(19):1783-1790.

11. Guan J, Fujimoto KL, Sacks MS, Wagner WR. Preparation and characterization of highly porous, biodegradable polyurethane scaffolds for soft tissue applications. Biomaterials. 2005;26(18):3961-3971.

12. Moriya A, Maruyama T, Ohmukai Y, Sotani T, Matsuyama H. Preparation of poly (lactic acid) hollow fiber membranes via phase separation methods. J Memb Sci. 2009;342(1-2):307-312.

13. Vozzi G, Flaim CJ, Bianchi F, Ahluwalia A, Bhatia S. Microfabricated PLGA scaffolds: a comparative study for application to tissue engineering. Mater Sci Eng C. 2002;20(1-2):43-47.

14. Tu C, Cai Q, Yang J, Wan Y, Bei J, Wang S. The fabrication and characterization of poly (lactic acid) scaffolds for tissue engineering by improved solid-liquid phase separation. Polym Adv Technol. 2003;14(8):565-573.

15. Ehrlich H, Krajewska B, Hanke T, et al. Chitosan membrane as a template for hydroxyapatite crystal growth in a model dual membrane diffusion system. J Memb Sci. 2006;273(1-2):124-128.

16. Gadegaard N, Martines E, Riehle MO, Seunarine K, Wilkinson CDW. Applications of nano-patterning to tissue engineering. Microelectronic Eng. 2006;83(4-9):1577-1581.

17. Wang Y, Liu Z, Han B, Gao H, Zhang J, Kuang X. A simple route to micropatterned polymer surfaces. Chem Commun (Camb). 2004 Apr 7; (7):800-801.

18. Wang Y, Liu Z, Han B, Sun Z, Zhang J, Sun D. Phase-separationinduced micropatterned polymer surfaces and their applications. $A d v$ Funct Mater. 2005;15(4):655-663.

19. Gunatillake PA, Adhikari R. Biodegradable synthetic polymers for tissue engineering. Eur Cell Mater. 2003;5:1-16.

20. Tokiwa Y, Calabia BP. Biodegradability and biodegradation of poly (lactide). Appl Microbiol Biotechnol. 2006;72(2):244-251.

21. Karim A, Slawecki TM, Kumar SK, et al. Phase-separation-induced surface patterns in thin polymer blend films. Macromolecules. 1998;31(3):857-862.

22. Tanaka T, Lloyd DR. Formation of poly (L-lactic acid) microfiltration membranes via thermally induced phase separation. J Memb Sci. 2004;238:65-73.

23. Kuo YC, Yeh CF, Yang JT. Differentiation of bone marrow stromal cells in poly (lactide-co-glycolide)/chitosan scaffolds. Biomaterials. 2009;30(34):6604-6613.
International Journal of Nanomedicine

\section{Publish your work in this journal}

The International Journal of Nanomedicine is an international, peerreviewed journal focusing on the application of nanotechnology in diagnostics, therapeutics, and drug delivery systems throughout the biomedical field. This journal is indexed on PubMed Central, MedLine, CAS, SciSearch $\AA$, Current Contents ${ }^{\circledR} /$ Clinical Medicine,

\section{Dovepress}

Journal Citation Reports/Science Edition, EMBase, Scopus and the Elsevier Bibliographic databases. The manuscript management system is completely online and includes a very quick and fair peer-review system, which is all easy to use. Visit http://www.dovepress.com/ testimonials.php to read real quotes from published authors. 